\title{
Hubungan antara Budaya Organisasi terhadap Senjangan Anggaran di Sekolah Inklusif dengan Peran Komitmen Organisasi sebagai Variabel Intervening
}

\author{
Risma Wira Bharata \\ rismawirab@untidar.ac.id \\ Program Studi Akuntansi, Fakultas Ekonomi, \\ Universitas Tidar, Magelang, Indonesia \\ Siti Afidatul Khotijah \\ khotijah_afi@untidar.ac.id \\ Program Studi Akuntansi, Fakultas Ekonomi, \\ Universitas Tidar, Magelang, Indonesia \\ Nibras Anny Khabibah \\ nibras@untidar.ac.id \\ Program Studi Akuntansi, Fakultas Ekonomi, \\ Universitas Tidar, Magelang, Indonesia
}

\begin{abstract}
This study aims to determine the relationship between organizational culture and budgetary slack, as well as the role of organizational commitment as an intervening variable for inclusive schools in Gunungkidul Regency. This survey research was conducted by dividing a questionnaire consisting of 6 questions on budgetary slack, 23 items on organizational culture, and 9 questions on organizational commitment. This study used a sample of 110 respondents who determined the sample based on purposive sampling. Path analysis in this study was used as data analysis using PLS 3.0 software. This study shows the results that with a t-statistic value of 1,822 the influence of organizational culture on organizational gaps, with a t-statistic value of 1,731 the influence of organizational culture on organizational commitment. Meanwhile, with the $t$-statistic 0.822 , organizational commitment has no effect on budgetary slack.
\end{abstract}

Keywords: budgetary slack; cultural organizations; organizational commitment

\begin{abstract}
Abstrak
Dalam penelitian ini bertujuan untuk mengetahui hubungan budaya organisasi dengan senjangan anggaran, serta peran komitmen organisasi sebagai variabel intervening untuk sekolah inklusi di Kabupaten Gunungkidul. Penelitian survei ini dilakukan dengan membagi kuesioner yang terdiri dari pertanyaan senjangan anggaran ada 6 butir, pertanyaan budaya organisasi ada 23 butir, dan pertanyaan komitmen organisasi ada 9 butir. Penelitian ini menggunakan sampel sebanyak 110 responden yang dengan menentukan sampel berdasarkan purposive sampling. Analisis jalur dalam penelitian ini digunakan sebagai analisis data menggunakan software PLS 3.0. Penelitian ini menunjukkan hasil bahwa dengan nilai tstatistic 1.822 pengaruh budaya organisasi pada senjangan organisasi, dengan nilai t-statistic 1.731 pengaruh budaya organisasi pada komitmen organisasi. Sedangkan dengan t-statistic 0.822 , komitmen organisasi tidak mempunyai pengaruh pada senjangan anggaran.
\end{abstract}

Kata kunci: senjangan anggaran; budaya organisasi; komitmen organisasi 


\section{PENDAHULUAN}

Sebuah sistem pendidikan yang mengakomodir siswa penyandang disabilitas untuk dapat bersekolah di sekolah umum merupakan pendidikan inklusif. Berdasarkan amanat UU tentang Sistem Pendidikan Nasional dan UU No 8 tahun 2016 mengenai Penyandang Disabilitas, satuan pendidikan tidak boleh mendiskriminasikan anak penyandang disabilitas untuk mengenyam pendidikan dari dasar sampai tinggi.

Penyelenggaraan pendidikan inklusif perlu kerjasama yang baik antara sekolah inklusif, dinas pendidikan dan masyarakat. Pendukung keberhasilan pendidikan inklusif dapat dilihat dari sarana dan prasarana yang aksesibel, guru pendamping yang tersedia, kurikulum yang adaptif dan dukungan masyarakat (Handayani dan Rahadian, 2013). Seandainya dari kerjasama tersebut tidak terlain dengan baik, maka pelaksanaan pendidikan inklusif tidak akan berjalan dengan baik. Kenyataan dilapangan mengatakan bahwa berdasarkan penelitian Hamidi (2016), pemerintah masih mendiskriminasikan penyandang disabilitas untuk memperoleh pendidikan tinggi dan masih ada kekosongan pada peraturan tentang aksesibilitas pekerjaan. Dilihat dari permasalahan tersebut, penulis dapat menarik kesimpulan bahwa hubungan kerjasama para stakeholder dalam pendidikan inklusif ini belum berjalan dengan baik. Biset (1998) dengan ringkas mengartikan stakeholder merupakan orang dengan perhatian pada permasalahan atau suatu kepentingan. Teori stakeholder meliputi pegawai, pemasok, pelanggan, media, komunitas lokal, LSM, bisa menjadi sumber ide dan peluang baru (Nikolova dan Arsic, 2017). Pengukuran penciptaan nilai stakeholder didasarkan pada kontribusi partner, itu penting karena teori stakeholder memperbaiki kinerja (Oubihi dan Elouidani, 2016).

Alasan penulis menggunakan variabel senjangan anggaran, budaya organisasi dan komitmen organisasi berdasarkan hasil penelitian Indriani \& Yusuf (2014) mengatakan bahwa dalam hubungan partisipasi anggaran terhadap senjangan anggaran, budaya organisasi dapat mempunyai pengaruh positif maupun negatif. Sejalan dengan penelitian itu, Peturuhu (2005) menjelaskan bahwa adanya hubungan negatif komitmen organisasi pada senjangan anggaran. Oleh karena itu, penulis akan memotret sekolah inklusif dari variabel tersebut. Penelitian ini bertujuan akan menguji hubungan budaya organisasi pada senjangan anggaran serta peran komitmen organisasi sebagai variabel intervening untuk sekolah inklusi di Kabupaten Gunungkidul. Pemilihan kabupaten Gunungkidul sebagai obyek penelitian karena sejak tahun 2014, kabupaten Gunungkidul merupakan kabupaten pertama yang mendeklarasikan sebagai kabupaten inklusif di Provinsi Daerah Istimewa Yogyakarta. Penelitian ini berkontribusi pada penguatan program pendidikan inklusif dalam pembentukan budaya organisasi yang inklusif dapat menumbuhkan komitmen organisasi bagi sekolah inklusif sehingga akan menurunkan senjangan anggaran dalam pelaksanaan pendidikan inklusif.

\section{LITERATUR REVIEW}

UU No 20 Tahun 2003 mengenai sistem pendidikan nasional menekankan agar menjalankan pendidikan inklusif sejak tahun 2003. Berdasarkan amanat tersebut, maka sedikit demi sedikit, sekolah umum bersedia untuk menerapkan pedidikan inklusif. Seharusnya budaya organisasi untuk menjalankan pendidikan inklusif sudah mulai terbentuk dengan kerjasama para stakeholder. Kerjasama stakeholder dalam melaksanakan pendidikan inklusi sangat diperlukan, dalam hal penyediaan sarana prasarana yang aksesibel, guru pendamping, dan kurikulum yang adaptif. Semua itu membutuhkan anggaran yang tidak sedikit. Dalam proses penyusunan program dan anggaran pendidikan inklusif, para stakeholder harus bersedia duduk bersama sehingga diharapkan tidak terjadi senjangan 
nggaran. Penelitian Indriani \& Yusuf (2014) mengatakan bahwa budaya organisasi memiliki pengaruh positif memperkuat partisipasi anggaran yang mempunyai hubungan pada senjangan anggaran. Hasil ini diperkuat oleh Prawira \& Wirasedana (2016) yang meneliti hubungan partisipasi anggaran dan senjangan anggaran yang dimediasi dengan budaya organisasi.

\section{$H_{1}$ : Budaya organisasi memiliki pengaruh negatif pada senjangan anggaran.}

Setiap anggota organisasi akan memperhatikan aspek budaya organisasi sebagai wujud rasa tanggung jawab yang akan ditimbulkan dari budaya organisasi tersebut karena merupakan hasil kesepakatan bersama. Hal tersebut mendorong timbulnya komitmen anggota pada organisasi yang menaunginya (Agusti, 2012). Penelitian Dewi dan Surya (2017) menemukan bahwa budaya organisasi mempunyai pengaruh positif pada komitmen organisasional.

\section{$\mathrm{H}_{2}$ : Budaya organisasi memiliki pengaruh positif pada komitmen organisasi.}

Pegawai yang mempunyai motivasi untuk merasa puas, maka pegawai tersebut akan tumbuh komitmen dalam mempertahankan diri dalam organisasi. Hal tersebut ditandai dengan tingkat ketidakhadiran yang rendah. Teori ini merupakan teori motivasi (Mathis \& Jackson, 2006). Semangat kerja merupakan faktor terpenting yang ditunjukkan dari keyakinan dan dukungan dari para pegawai pada nilai dan sasaran yang akan organisasi capai (Tunti 2008). Komitmen yang tinggi dari dinas pendidikan dengan sekolah inklusi dalam melakukan partisipasi yang saling menguntungkan untuk mengusulkan informasi agar terwujudnya tujuan bersama sangat dibutuhkan dalam menjalankan pendidikan inklusi (Bharata, Pramudyastuti, Sunaningsih, 2020). Jika individu mementingkan kepentingan pribadi atau memiliki komitmen organisasi yang rendah, maka individu tersebut dalam melakukan partisipasi anggaran akan berusaha meminimalkan senjangan anggaran supaya kinerjanya bagus. Begitupun sebaliknya, jika individu mempunyai komitmen organisasi yang tinggi, maka senjangan anggaran yang dilakukan akan rendah (Apriadinata, Sujana, \& Adi Putra, 2014). Penelitian (Puturuhu, 2005) menyimpulkan hubungan negatif antara komitmen organisasi dengan senjangan anggaran. Hal ini artinya semakin rendah komitmen organisasi maka semakin tinggi senjangan anggaran, dan begitu pula sebaliknya.

$H_{3}$ : Komitmen organisasi memiliki pengaruh negatif pada senjangan anggaran.

\section{METODE PENELITIAN}

Penelitian ini menggunakan metode kuantitatif yang menggunakan survei dengan menyebarkan kuesioner kepada 110 responden yang terlibat dalam pendidikan inklusi. Penentuan sampel dengan metode purposive sampling dengan kriteria yaitu sekolah inklusi dan pegawai Dinas Pendidikan yang bekerja dalam perencanaan dalam sekolah inklusi di Kabupaten Gunungkidul. Instrumen penelitian menggunakan skala Likert, kemudian dianalisis menggunakan Partial Least Squares (PLS).

\section{HASIL DAN PEMBAHASAN}

Penelitian ini dalam menganalisis data dengan aplikasi PLS, (Hartono \& Abdilah, 2009), dengan penjelasan sebagai berikut: 


\section{Merancang dan Mengevaluasi Model Pengukuran}

Tabel 1. Evaluasi Model Pengukuran

\begin{tabular}{lcccc}
\hline & AVE & $\begin{array}{c}\text { Composite } \\
\text { Reliability }\end{array}$ & R Square & $\begin{array}{c}\text { Cronbachs } \\
\text { Alpha }\end{array}$ \\
\hline Budaya Organisasi & 0.540 & 0.963 & 0.145 & 0.962 \\
Komitmen Organisasi & 0.568 & 0.921 & 0.100 & 0.905 \\
Senjangan Anggaran & 0.585 & 0.890 & 0.145 & 0.868 \\
\hline
\end{tabular}

\section{Sumber: Olah Data}

\section{Uji Validitas Konstruk}

Uji validitas konstruk dengan hasil olah skor AVE untuk konstruk budaya organisasi dengan angka 0,540, komitmen organisasi dengan angka 0,568, dan senjangan anggaran dengan angka 0,585. Parameter untuk loading factor dan average variance extracted (AVE) yang mengukur konstruk harus melebihi 0,50.

\section{Uji validitas konvergen}

Uji validitas konvergen dengan hasil olah semua skor AVE dari konstruk-konstruk tersebut terpenuhi syarat-syarat untuk lebih dari 0,5 (Hartono \& Abdilah, 2009). Konstruk senjangan anggaran paling tinggi dengan skor AVE 0,585.

\section{Uji validitas diskriminan}

Uji validitas diskriminan dari semua indikator dalam penelitian ini telah terpenuhi syaratsyarat validitas diskriminan dengan perbandingan akar AVE setiap konstruk dengan korelasi antara konstruk yang satu dan konstruk yang lain.

Tabel 2. Average Variance Extracted (AVE)

\begin{tabular}{lcc}
\hline \multicolumn{1}{c}{ Indikator } & AVE & Akar AVE \\
\hline Budaya Organisasi & 0.540 & 0,734846922 \\
Komitmen Organisasi & 0.568 & 0,753657747 \\
Senjangan Anggaran & 0.585 & 0,764852927 \\
\hline
\end{tabular}

Sumber: Olah Data

Tabel 3. Korelasi Variabel Laten

\begin{tabular}{lccc}
\hline & $\begin{array}{c}\text { Budaya } \\
\text { Organisasi }\end{array}$ & $\begin{array}{c}\text { Komitmen } \\
\text { Organisasi }\end{array}$ & $\begin{array}{c}\text { Senjangan } \\
\text { Anggaran }\end{array}$ \\
\hline Budaya Organisasi & 1.000 & & \\
Komitmen Organisasi & 0.293 & 1.000 & \\
Senjangan Anggaran & 0.354 & 0.229 & 1.000 \\
\hline Sumber: Olah Data & & &
\end{tabular}

\section{Uji reliabilitas}

Dalam penelitian ini, semua instrumen terpenuhi uji validitas dan uji reliabilitas sehingga dapat dilakukan untuk pengujian hipotesis. Uji reliabilitas untuk semua konstruk dalam penelitian ini terpenuhi uji reliabilitas dengan tolok ukur Cronbach's alpha dan Composite reliability yang melebihi 0,7 .

Tabel 4. Skor Cronbach's Alpha dan Composte Reliability Cronbach's Alpha Composite Reliability 


\begin{tabular}{lll}
\hline Budaya Organisasi & 0.962 & 0.963 \\
Komitmen Organisasi & 0.905 & 0.921 \\
Senjangan Anggaran & 0.868 & 0.890 \\
\hline Sumber: Olah Data &
\end{tabular}

\section{Merancang dan Mengevaluasi Model Struktural}

Berdasarkan hasil pengolahan PLS untuk model struktural, maka dapat dilihat nilai $\mathrm{R}^{2}$ untuk konstruk budaya organisasi dengan angka 0,145, konstruk variabel komitmen organisasi dengan angka 0,100 , dan konstruk variabel senjangan anggaran dengan angka 0,145 , sedangkan sisanya dijelaskan oleh variabel lain di luar model.

\section{Pengujian Hipotesis}

Pengujian hipotesis pada penelitian ini menggunakan model struktural dengan memakai fungsi bootstrapping. Berikut ini disajikan hasil dari pengolahan bootstrapping:

Tabel 5. Koefisien Jalur (Path Coeficients; Mean, STDEV, T-Values)

\begin{tabular}{|c|c|c|c|c|c|c|}
\hline & & $\begin{array}{c}\text { Original } \\
\text { Sample } \\
(O)\end{array}$ & $\begin{array}{c}\text { Sample } \\
\text { Mean } \\
(M)\end{array}$ & $\begin{array}{l}\text { Standard } \\
\text { Deviation } \\
\text { (STDEV) }\end{array}$ & P-Value & $\begin{array}{c}\text { T Statistics } \\
(\mid \text { O/STERR } \mid)\end{array}$ \\
\hline $\begin{array}{l}\text { Budaya Organisasi } \\
\text { Komitmen Organisasi }\end{array}$ & $->$ & 0.245 & 0.241 & 0.199 & 0.219 & 1.731 \\
\hline $\begin{array}{l}\text { Budaya Organisasi } \\
\text { Senjangan Anggaran }\end{array}$ & $->$ & 0.295 & 0.281 & 0.162 & 0.069 & 1.822 \\
\hline $\begin{array}{l}\text { Komitmen Organisasi } \\
\text { Senjangan Anggaran }\end{array}$ & $->$ & 0.131 & 0.131 & 0.159 & 0.411 & 0.822 \\
\hline
\end{tabular}

Sumber: Olah Data

Berdasarkan pada tabel koefisien jalur yang telah dijelakan di atas menyimpulkan bahwa budaya organisasi memiliki pengaruh secara negatif terhadap senjangan anggaran. Hal ini dapat diartikan jika budaya organisasi sekolah inklusi naik, maka senjangan anggaran pada sekolah inklusi akan turun, atau sebaliknya. Pernyataan ini dapat dilihat dari nilai t-statistic dengan angka 1.822 yang melebihi nilai t-tabel yang dipersyaratkan 1,64 dan nilai koefisien jalur $(\gamma 1)$ 0.295. Oleh karena itu, $\mathrm{H}_{1}$ terdukung (dapat diterima).

Tabel koefisien jalur yang telah disampaikan di atas menyimpulkan bahwa budaya organisasi berpengaruh secara positif serta berpengaruh signifikan terhadap komitmen organisasi. Hal ini diartikan apabila budaya organisasi sekolah inklusi akan naik, maka komitmen organisasi pegawai sekolah inklusi juga akan naik, maupun sebaliknya. Hal ini dapat dilihat dari nilai T-statistic dengan angka 1.731 yang melebihi nilai T-tabel yang dipersyaratkan 1,64 dan nilai koefisien jalur $(\gamma 1)$ 0.245. Oleh karena itu, $\mathrm{H}_{2}$ terdukung atau dapat diterima.

Hasil penelitian ini mendukung penelitian Usmany (2016) dan penelitian Dewi dan Surya (2017) yang mengatakan bahwa budaya organisasi memiliki pengaruh positif terhadap komitmen organisasi.

Tabel koefisien jalur yang disampaikan di atas memberikan kesimpulan bahwa komitmen organisasi tidak mempunyai pengaruh secara positif terhadap senjangan anggaran. Hal ini diartikan apabila komitmen organisasi sekolah inklusi naik, belum tentu senjangan anggaran juga naik, ataupun sebaliknya. Hal ini dapat dilihat dari nilai t-statistic dengan angka 0.822 yang kurang dari nilai t-tabel yang dipersyaratkan 1,64 dan nilai koefisien jalur $(\gamma 1) 0.131$. Oleh karena itu, $\mathrm{H}_{3}$ tidak didukung atau tidak diterima. 
Tabel 6. Ringkasan hasil pengujian hipotesis

\begin{tabular}{cccccc}
\hline Hipotesis & Hubungan & Tanda & Koefisien & T-statistic & Hasil \\
\hline $\mathrm{H}_{1}$ & $\mathrm{BO} \rightarrow \mathrm{SA}$ & - & 0.295 & 1.822 & Terdukung \\
$\mathrm{H}_{2}$ & $\mathrm{BO} \rightarrow \mathrm{KO}$ & + & 0.245 & 1.731 & Terdukung \\
$\mathrm{H}_{3}$ & $\mathrm{KO} \rightarrow \mathrm{SA}$ & - & 0.131 & 0.822 & Tidak Terdukung \\
\hline
\end{tabular}

Catatan: $1,64 \mathrm{P}<0,05 ; 2,33 \mathrm{P}<0,01$ (one-tailed).

\section{Analisis Pengaruh Langsung dan Tidak langsung}

Penelitian ini menggunakan variabel intervening yang memberikan hubungan antara budaya organisasi dan senjangan anggaran, yaitu komitmen organisasi. Tahapan-tahapan untuk pengujian efek intervening (Hartono, 2011) adalah 1) pengujian efek utama variabel independen terhadap variabel dependen (pengaruh budaya organisasi terhadap senjangan anggaran), harus signifikan, 2) menguji pengaruh variabel independen ke variabel mediasi (budaya organisasi pada komitmen organisasi, harus signifikan, dan 3) menguji pengaruh variabel mediasi pada variabel dependen (komitmen organisasi ke senjangan anggaran), harus signifikan. Karena tahapan ketiga tidak terpenuhi (tidak signifikan), maka komitmen organisasi tidak terbukti memediasi hubungan antara budaya organisasi dan senjangan anggaran.

\section{SIMPULAN}

Penelitian ini dilakukan untuk menguji hubungan budaya organisasi pada senjangan anggaran, serta peran komitmen organisasi sebagai variabel intervening untuk sekolah inklusi di Kabupaten Gunungkidul. Kesimpulan dari penelitian ini menunjukkan bahwa 2 hipotesis terdukung dan 1 hipotesis tidak terdukung. Budaya organisasi mempunyai pengaruh negatif pada senjangan anggaran dan budaya organisasi mempunyai pengaruh positif pada komitmen organisasi. Sedangkan, komitmen organisasi tidak mempunyai pengaruh pada senjangan anggaran, sehingga hipotesis ke-3 tidak diterima.

Berdasarkan hasil penelitian sebelumnya, ditemukan beberapa hasil analisis yang dapat dipertimbangkan bagi pihak terkait. Sekolah inklusi dan dinas pendidikan diharapkan mempertahankan budaya organisasi yang sudah terbentuk agar mereka dapat bekerja dengan baik dalam menjalankan program pendidikan inklusi. Sekolah inklusi dan dinas pendidikan diharapkan meningkatkan komitmen organisasi dalam menjalankan program pendidikan inklusi karena sekolah inklusi tidaklah sama dengan sekolah umum. Sekolah inklusi harus memahami kebutuhan para disabilitas dalam hal pendidikan. Sekolah inklusi dan dinas pendidikan diharapkan untuk selalu menurunkan senjangan anggaran agar sekolah inklusi menjalankan program pendidikan inklusi dengan baik.

Berdasarkan pada hasil penelitian ini, maka penulis mengajukan beberapa saran, bahwa budaya organisasi dan komitmen organisasi di sekolah inklusi harus selalu ditingkatkan agar dapat menurunkan senjangan anggaran sehingga sekolah inklusi dapat menjalankan program pendidikan inklusi secara maksimal sesuai amanah Undang-Undang No 20 Tahun 2003 dan Undang-Undang No 8 Tahun 2016.

\section{REFERENSI}

Agusti, R. (2012). Pengaruh partisipasi penyusunan anggaran terhadap kinerja aparatur pemerintah daerah dengan dimoderasi oleh variabel desentralisasi dan budaya organisasi. Jurnal Ekonomi Universitas Riau, 20(3). 
Alfebriano. (2013). Faktor-faktor yang mempengaruhi slack anggaran pada PT BRI di Kota Jambi. e-Jurnal Binar Akuntansi .

Anthony, R. N., \& Govindarajan, V. (2000). Management control system. U.S.: The McGraw-Hill.

Apriadinata, M. D., Sujana, E., \& Adi Putra, M. P. (2014). Pengaruh partisipasi anggaran, penekanan anggaran, komitmen organisasi, dan asimetri informasi terhadap slack anggaran dengan kompleksitas tugas sebagai variabel moderasi (studi kasus pada BPR di Kota Singaraja . e-Jurnal S1 Ak Universitas Pendidikan Ganesha 2(1).

Arifah, D. A. (2012). Praktek teori agensi pada entitas publik dan nonpublik. Prestasi 9(1), 85-95.

Arikunto, S. (1997). Prosedur penelitian suatu pendekatan praktek. Jakarta: PT Rineka Cipta.

Bharata, R. W, Pramudyastuti, O. L, \& Sunaningsih, S. N. (2020). Pengaruh Partisipasi Anggaran terhadap Senjangan Anggaran dengan Komitmen Organisasi sebagai Variabel Intervening. Jurnal Riset Akuntansi dan Komputerisasi Akuntansi 11 (1), 158178.

Brownell, P., \& McInnes, M. (1986). Budgetary participation, motivation, and managerial performance. The Accounting Review, 61(4), 587-600.

Budi, T. A. (2013). Pengaruh penganggaran partisipatif terhadap budgetary slck dengan asimetri informasi dan budget emphasis sebagai variabel pemoderasi (studi kasus pada PEMDA Kabupaten Sleman). Yogyakarta: Tesis Akuntansi UGM.

Camilleri, E., \& Van Der Heijden, B. I. (2007). Organization commitment, public service motivation, and performance within the public sector. Public Performance \& Management Review, 31(2), 241-274.

Creswell, John, W \& Clark, Vicki, L, Plano (2011). Designing and conducting mixed methods research. SAGE Publication.

Devi, E. (2009). Analisis pengaruh kepuasan kerja dan motivasi terhadap kinerja karyawan dengan komitmen organisasional sebagai variabel intervening. Semarang: Tesis Manajemen Universitas Diponegoro.

Dewi, N. M., \& Sudana, I. P. (2013). Pengaruh penganggaran partisipatif pada senjangan anggaran dengan budgetary control dan komitmen organisasi sebagai variabel pemoderasi. E-Jurnal Akuntansi Univervitas Udayana, 707-722.

Dewi, Ratna, I Gusti Ayu Ketut \& Surya, Ida Bagus Ketut. (2017). Pengaruh budaya organisasi terhadap komitmen organisasional dan organizational silence pada PT. PLN (Persero) Rayon Denpasar. E-Jurnal Manajemen Unud, 6(1), 289-316.

Djasuli, M., \& Fadilah, N. I. (2011). Efek interaksi informasi asimetri, budaya organisasi, group cohensiveness dan motivasi dalam hubungan kausal antara budgeting partisipation dan budgetary slack. Jurnal PESAT Universitas Ganadarma, 4.

Douglas, P. C., \& Wier, B. (2000). Integrating ethical dimensions into a model of budgetary slack creation. Journal of Business Ethics 28( 3), 267-277.

Dunk, A. S. (1993). The effect of budget emphasis and information asymetry on the relation between budgetary partisipaton and slack. The Accounting Review, 68(2), 400-410.

Efendi, M. (2005). Pengantar psikopedagogik anak berkelainan. Malang: Bumi Aksara.

Eisenhardt, K. M. (1989). Agency theory: assessment and review . The Academy of Management Review, 14(1), 57-74.

Falikhatun. (2007). Interaksi informasi asimetri, budaya organisasi, dan group cohensiveness dalam hubungan antara partisipasi penganggarann dan budgetary slack. SNA $X$.

Firdaus. (2006). Pengaruh kelekatan misi, budaya organisasi, dan lingkungan pekerjaan terhadap kinerja pegawai instansi pemerintah komitmen organisasi sebagai variabel perantara. Yogyakarta: Tesis Akuntansi MSi UGM. 
Gibson, J. L., Ivancevich, J. M., \& Donnelly, J. H. (1996). Organisasi, Edisi 8 Jilid 1. Jakarts: Binarupa Aksara.

Grediani, E. (2010). Pengaruh Tekanan dan tanggungjawab persepsian pada penciptaan budgetary slack. Yogyakarta: Tesis Akuntansi UGM.

Gudo (2012). Analisis Data multivariat. Yogyakarta: BPFE.

Hafsah. (2005). Pengaruh asimetri informasi dan komitmen organisasi terhadap hubungan antara partisipasi anggaran dan kesenjangan anggaran. $e$-Jurnal USU.

Hartono, J. (2011). Konsep dan aplikasi structural equation modeling berbasis varian dalam penelitian bisnis. Yogyakarta: UPP STIM YKPN.

Hartono, J. (2010). Metodologi penelitian bisnis salah kaprah dan pengalaman-pengalaman edisi pertama. Yogyakarta: BPFE.

Ikhsan, A., \& Ane, L. (2007). Pengaruh partisipasi anggaran terhadap senjangan anggaran dengan menggunakan lima variabel pemoderasi. SNA $X$.

Iskandar, Z. A. (2011). Kualitas pelayanan badan layanan umum transjakarta pada penumpang panyandang cacat fisik (difabel). Serang: Skripsi FISIP Universitas Sultan Ageng Tirtayasa.

Jensen, \& Meckling. (1976). Theory of the firm: managerial behavior, agency costs, and ownership structure. Journal of financial Economics. 3, 305-360.

Kartika, A. (2010). The effect of organizational commitment and uncertainty environment on the relationship between budget participation. Kajian Akuntansi 2(1), 39-60.

Khan, M. R., Ziauddin, Jam, F. A., \& Ramay, M. (2010). The impact of organizational commitment on employee job performance. European Journal of Social Sciences, 15(3) , 292-298.

Kim, D. (1992). Risk preferences in participation budgeting. The Accounting Review, 67(2), 303-318.

Latan, H., \& Ghozali, I. (2012). Partial least squares: konsep, teknik, dan aplikasi menggunakan program SmartPLS 2.0 M3 . Semarang: Badan Penerbit Universitas Diponegoro.

Latifah, N. (2010). Is there of opportunistic behavior on the agency theory aplication in the public sector ? Economic Focus, 5(2), 85-94.

Latuheru, B. P. (2005). Pengaruh partisipasi anggaran terhadap senjangan anggaran dengan komitmen organisasi sebagai variabel moderating. Jurnal Akuntansi dan Keuangan, 7( 2), 117-126.

Ma'rif, S., Nugroho, P., \& Wijayanti, L. (2010). Evaluasi efektivitas pelaksanaan musyawarah perencanaan pembangunan Kota Semarang. Riptek, 4(I1), 53 - 62.

Magee, R. P. (1980). Equilibria in budget participation. Journal of Accounting Research,18(2), 551-573.

Mangkunegara, A. A. (2005). Evaluasi kinerja SDM. Bandung: PT Refika Aditama.

Margono. (1996). Metodologi penelitian pendidikan. Semarang: Rineka Cipta.

Mathis, R. L., \& Jackson, J. H. (2006). Human resource management. Jakarta: Salemba Empat.

Milani, K. (1975). The Relationship of participation in budget-setting to industrial supervisor performance and attitudes: a field study. The Accounting Review, 50(2), 274-284.

Muhadi. (2007). Analisis pengaruh kepuasan kerja terhadap komitmen organisasional dalam mempengaruhi kinerja karyawan. Semarang: Tesis Manajemen Universitas Diponegoro.

Mujimin. (2007). Penyediaan fasilitas publik yang manusiawi bagi aksesibilitas difabel. Dinamika Pendidikan No 1 .

Nikolova, Ventsislava \& Arsić, Sanela. (2017). The stakeholder approach in corporate social responsibility. Engineering management 3 (1) 24-35 
Nugraha, M. (2008). Peran dimensi-dimensi komitmen organisasional terhadap hubungan antara partisipasi penganggaran dan senjangan anggaran di departemen pendidikan nasional. Yogyakarta: Tesis Akuntansi UGM.

Nurcahyani, Kunwaviyah, (2010), Pengaruh partisipasi anggaran terhadap kinerja manajerial melalui komitmen organisasi dan persepsi inovasi sebagai variabel intervening, Skripsi Akuntansi FEB Universitas Diponegoro, Semarang

Onci, M. (1973). Factor analysis of behavioral variables affecting budgetary slack. The Accounting Review, 48(3), 535-548.

Oubihi, Jamila \& Elouidani, Abdelkbir. (2016). The stakeholder value: contributions and limitations. International Journal of Business and Social Science,7(4).

Prawira, H., \& Wirasedana, P. I. (2016). Budaya organisasi sebagai prediktor partisipasi penganggaran dan implikasinya pada senjangan anggaran. E-Jurnal Akuntansi, 14(1), $144-171$.

Peraturan Pemerintah No. 43 Tahun 1998. Indonesia

Peraturan Pemerintah No. 08 Tahun 2008. Indonesia

Peraturan Daerah Provinsi DIY No. 04 Tahun 2011. Indonesia

Putranto, A. Y. (2012). Pengaruh moderasi informasi asimetri dan group cohesiveness tehadap hubungan partispasi anggaran dan budgetary slack. Jurnal Economica, 8(2).

Puturuhu, W. (2005). Pengaruh partisipasi anggaran terhadap senjangan anggaran dengan komitmen organisasional sebagai variabel pemoderat: studi pada pemerintah Kota Ambon. Yogyakarta: Tesis Akuntansi UGM.

Raharjo, E. (2007). Agency theory and stewardship theory in the accounting perspective. Fokus Economi 2(1), 37-46.

Rahayu. (2009). Hubungan antara komitmen organisasi, kepuasaan kerja dan niat berpindah auditor . Yogyakarta: Tesis Akuntansi MSi FEB UGM.

Riduwan. (2004). Metode dan teknik menyusun tesis. Bandung: Alfabeta.

Roebyantho, H., Sumarno, S., \& Mujiyadi. (2010). Penelitian pola multi layanan pada panti sosial penyandang cacat. Jakarta: Badan Pendidikan dan Penelitian Kesejahteraan Sosial Pusat Penelitian dan Pengembangan Kesejahteraan Sosial Kementerian Sosial RI.

Roebyantho, H., Sumarno, S., \& Nainggolan, T. (2009). Evaluasi program pemberian bantuan dana jaminan sosial bagi penyandang cacat berat. Jakarta: Badan Pendidikan dan Penelitian Kesejahteraan Sosial Pusat Penelitian dan Pengembangan Kesejahteraan Sosial Kementerian Sosial RI.

Santoso, S. (2005). Pengaruh partisipasi anggaran, komitmen organisasi, dan keterlibatan pekerjaan terhadap senjangan anggaran pada penyusunan APBD Kota Semarang. Yogyakarta: Tesis Akuntansi UGM.

Sardjito B, Muthaher O, (2007), Pengaruh partisipasi penysunan anggaran terhadap kinerja aaparat pemerintah daerah: budaya organisasi dan komitmen organisasi sebagai variabel moderating, Universitas Islam Sultan Agung, SNA Unhas

Scott, W. R. (2009). Financial accouting theory. Canada: PEARSON Prentice Hall .

Sembiring, Etti Ernita, (2006), Pengaruh informasi asimetris, alokasi sumber daya, etika, dan komitmen organisasi terhadap budget slack, Tesis Akuntansi FEB Universitas Gadjah Mada, Yogyakarta

Siagian, S. P. (2007). Manajemen sumber daya manusia. Jakarta: Bumi Aksara.

Steers, R. M. (1977). Antecedents and outcomes of organizational commitment. Administrative Science Quarterly 22(1) , 46-56.

Stroh, L. K., Brett, J. M., Baumann, J. P., \& Reilly, A. H. (1996). Agency theory and variable pay compensation strategies. Academy of Mmanagement Journal, 39( 3), 751-767.

Sugiyono, (2006), Statistika untuk penelitian, Bandung: Alfabeta. 
Suhendro, S. (2008). Peran moderasi tekanan sosial dalam hubungan antara partisipasi penyusunan anggaran dengan senjangan anggaran pada APBD. Yogyakarta: Tesis Akuntansi UGM.

Sujana, I Ketut, (2010), Pengaruh partisipasi penganggaran, penekanan anggaran, komitmen organisasi, asimetri informasi, dan ketidakpastian lingkungan terhadap budgetary slack pada hotel-hotel berpintang di Kota Denpasar, Akuntansi FE Universitas Udayana, Bali

Tunti, M. E. (2008). Analisis pengaruh kepuasan kerja, komitmen organisasi, dan motivasi terhadap kinerja manajerial pemerintah daerah. Yogyakarta: Tesis Akuntansi MSi UGM.

Undang-Undang No 4 Tahun 1997. Indonesia.

Undang-Undang No 19 Tahun 2011. Indonesia

Uno, H. B. (2006). Teori motivasi \& pengukurannya. Gorontalo: PT Bumi Aksara.

Usman, H. (2006). Manajemen teori, praktik, dan riset pendidikan. Yogyakarta: Bumi Aksara.

Ustadi MH, Ustami RD, (2003), Analisis perbedaan faktor-faktor individual terhadap persepsi perilaku etis mahasiswa, Jurnal Akuntood \& Auditing, 1(2), $162-180$

Young, M. S. (1985). Participative budgeting: the effects of risk aversion and asymmetric information on budgetary slack. Journal of Accounting Research, 23(2), 829-842.

Yusnaini. (2011). Agency Theory dan management control systems dalam konteks budaya Asia. Jurnal Ekonomi dan Informasi Akuntansi 1(1), 37-45. 